\title{
On Computability and Applicability of Mann-Reich-Sabach-Type Algorithms for Approximating the Solutions of Equilibrium Problems in Hilbert Spaces
}

\author{
F. O. Isiogugu $\mathbb{D},{ }^{1,2}$ P. Pillay, ${ }^{1}$ and P. U. Nwokoro ${ }^{2}$ \\ ${ }^{1}$ School of Mathematics, Statistics and Computer Sciences, University of KwaZulu-Natal, Westville Campus, \\ Durban 4000, South Africa \\ ${ }^{2}$ Department of Mathematics, University of Nigeria, Nsukka, Nigeria
}

Correspondence should be addressed to F. O. Isiogugu; felicia.isiogugu@unn.edu.ng

Received 18 November 2017; Revised 10 May 2018; Accepted 16 September 2018; Published 1 October 2018

Academic Editor: Sining Zheng

Copyright (C) 2018 F. O. Isiogugu et al. This is an open access article distributed under the Creative Commons Attribution License, which permits unrestricted use, distribution, and reproduction in any medium, provided the original work is properly cited.

\begin{abstract}
We establish the existence of a strong convergent selection of a modified Mann-Reich-Sabach iteration scheme for approximating the common elements of the set of fixed points $F(T)$ of a multivalued (or single-valued) $k$-strictly pseudocontractive-type mapping $T$ and the set of solutions $E P(F)$ of an equilibrium problem for a bifunction $F$ in a real Hilbert space $H$. This work is a continuation of the study on the computability and applicability of algorithms for approximating the solutions of equilibrium problems for bifunctions involving the construction of a sequence $\left\{K_{n}\right\}_{n=1}^{\infty}$ of closed convex subsets of $H$ from an arbitrary $x_{0} \in H$ and a sequence $\left\{x_{n}\right\}_{n=1}^{\infty}$ of the metric projections of $x_{0}$ into $K_{n}$. The obtained result is a partial resolution of the controversy over the computability of such algorithms in the contemporary literature.
\end{abstract}

\section{Introduction}

Let $H$ be a real Hilbert space with an inner product $\langle.,$.$\rangle and a$ norm $\|$.$\| , respectively and let K$ be a nonempty closed convex subset of $H$. Let $A: H \longrightarrow H$ be an operator on $H$ and $F$ : $K \times K \longrightarrow \mathbb{R}$ be a bifunction on $K$, where $\mathbb{R}$ is the set of real numbers. The variational inequality problem of $A$ in $K$ denoted by $\operatorname{VIP}(A, K)$ is to find an $x^{*} \in K$ such that

$$
\left\langle x-x^{*}, A\left(x^{*}\right)\right\rangle \geq 0, \quad \forall x \in K,
$$

while the equilibrium problem for $F$ is to find $x^{*} \in K$ such that

$$
F\left(x^{*}, x\right) \geq 0, \quad \forall x \in K .
$$

The set of solutions of (2) is denoted by $E P(F)$. Suppose $F(x, y)=\langle y-x, A x\rangle$ for all $x, y \in K$, then $w \in E P(F)$ if and only if $w$ is a solution of (1). Many problems in optimization, economics, and physics reduce to finding a solution of (1) (see, for example, [1-3]) and the references therein. The following conditions are assumed for solving the equilibrium problems for a bifunction $F: K \times K \longrightarrow \mathbb{R}$,
(A1) $F(x, x)=0$ for all $x \in K$.

(A2) $F$ is monotone, that is, $F(x, y)+F(y, x) \leq 0$, for all $x, y \in K$.

(A3) For each $x, y, z \in K, \lim _{t \downarrow 0} F(t z+(1-t) x, y) \leq F(x, y)$.

(A4) For each $x \in K, y \longmapsto F(x, y)$ is convex and lower semicontinuous.

Several algorithms have been introduced by authors for approximating the solutions of an equilibrium problem for a bifunction (or the common elements of the sets of solutions of equilibrium problems for a finite family of bifunctions). Many authors have also approximated the common elements of the set of fixed points $F(T)$ of a multivalued (or single-valued) mapping $T$ and the set of solutions $E P(F)$ of an equilibrium problem for a bifunction $F$ (or the common elements of the sets of fixed points of a finite family of multivalued (or single-valued) mappings and the sets of solutions of equilibrium problems for a finite family of bifunctions) (see, for example, [4-10] and references therein). In a real Hilbert space, many authors have studied the algorithms involving 
the construction of the sequences of sets $\left\{K_{n}\right\}_{n=1}^{\infty}$ and the metric projections $\left\{x_{n}\right\}_{n=1}^{\infty}$, from an arbitrary $x_{0} \in H$, where $K_{n+1}=\left\{z \in K_{n}:\left\|z-u_{n}\right\|^{2} \leq\left\|z-x_{n}\right\|^{2}\right\}, x_{n+1}=P_{K_{n+1}} x_{0}$, while $P_{K_{n}}$ is the projection map and $\left\{u_{n}\right\}_{n=1}^{\infty}$ is the sequence of the resolvent of the bifunctions, (see, for example, $[4,9]$ and references therein).

Among the iteration schemes studied are the modified Reich-Sabach-type Algorithm 1 and Mann-Reich-Sabachtype Algorithm 2 below defined for the approximation of (i) the solutions of an equilibrium problem for a bifunction; (ii) the common elements of the set of fixed points $F(T)$ of a multivalued (or single-valued) mapping $T$, and the set of solutions $E P(F)$ of an equilibrium problem for a bifunction $F$ respectively.

(i) Let $H$ be a real Hilbert space and $K$ a closed and convex subset of $H$. Let $F: K \times K \longrightarrow \mathbb{R}$ be a bifunction and $r \in$ $[a, \infty)$ for some $a>0$. Then from an arbitrary $x_{0} \in H$ the algorithm is generated as follows.

Algorithm 1.

$$
\begin{aligned}
y_{n} & =x_{n} \\
u_{n} & \in K \text { such that } F\left(u_{n}, y\right)+\frac{1}{r}\left\langle y-u_{n}, u_{n}-y_{n}\right\rangle \\
& \geq 0, \quad \forall y \in K, \\
K_{n+1} & =\left\{z \in K_{n}:\left\|z-u_{n}\right\|^{2} \leq\left\|z-x_{n}\right\|^{2}\right\} \\
x_{n+1} & =P_{K_{n+1}} x_{0} .
\end{aligned}
$$

(ii) Let $H$ be a real Hilbert space, $K$ a closed and convex subset of $H, F: K \times K \longrightarrow \mathbb{R}$ a bifunction, and $T: K \longrightarrow P(K)$ multivalued $k$-strictly pseudocontractive-type mapping. Let $\left\{\alpha_{n}\right\}_{n=1}^{\infty} \subset[0,1]$ and $r \in[a, \infty)$ for some $a>0$. Then from an arbitrary $x_{0} \in H$ the algorithm is generated as follows.

Algorithm 2.

$$
\begin{aligned}
y_{n} & =\alpha_{n} x_{n}+\left(1-\alpha_{n}\right) v_{n} \\
u_{n} & \in K \text { such that } F\left(u_{n}, y\right)+\frac{1}{r}\left\langle y-u_{n}, u_{n}-y_{n}\right\rangle \\
& \geq 0, \quad \forall y \in K, \\
K_{n+1} & =\left\{z \in K_{n}:\left\|z-u_{n}\right\|^{2} \leq\left\|z-x_{n}\right\|^{2}\right\} \\
x_{n+1} & =P_{K_{n+1}} x_{0},
\end{aligned}
$$

where $v_{n} \in T x_{n}$ for multivalued mapping $T$.

However, despite the fact that most of these algorithms yield strong convergence theoretically, the difficulty encountered by computers with the construction of the sequence of the metric projection $\left\{x_{n}\right\}_{n=1}^{\infty}$ and the sequence of sets $\left\{K_{n}\right\}_{n=1}^{\infty}$ has made such algorithms almost impossible for real life applications. This noncomputability and nonapplicability of such algorithms has led to the introduction of other algorithms which do not involve the construction of these two sequences but require stronger conditions and many parameters in the hypothesis of their convergence theorems.

One of these important algorithms is the algorithm of Zhaoli Ma et al. [10].

The purpose of this research is to develop a computable version of Algorithms 1 and 2. In particular, it is established that given the modified Reich-Sabach-types Algorithm 1 for approximating the solutions of an equilibrium problem $\mathrm{EP}(\mathrm{F})$ for a bifunction $F: K \times K \longrightarrow \mathbb{R}$ in a real Hilbert space $H$ involving the construction of the sequences $\left\{K_{n}\right\}_{n=1}^{\infty}$ and $\left\{x_{n}\right\}_{n=1}^{\infty}$ from an arbitrary $x_{0} \in H$, where $K=K_{0}$ is a closed and convex subset of $H, K_{n+1}=\left\{z \in K_{n}:\left\|z-u_{n}\right\|^{2} \leq\right.$ $\left.\left\|z-x_{n}\right\|^{2}\right\}$, and $x_{n+1}=P_{K_{n+1}} x_{0}$, while $P_{K_{n}}$ is the metric projection of $H$ into $K_{n}$ and $\left\{u_{n}\right\}_{n=1}^{\infty}$ is the sequence of the resolvents of the bifunction; there exists a selection $\left\{k_{n}\right\}_{n=1}^{\infty}$ of $\left\{K_{n}\right\}_{n=1}^{\infty}$ which converges strongly to a solution of the equilibrium problem. Furthermore, if the norm on $H$ is order inclusion transitive on the closed convex subsets $C C(H)$ of $H$, then $x_{n+1}=P_{K_{n+1}} x_{0}$ and the selection converges strongly to $P_{E P(F)} x_{0}$. Where a norm $\|$.$\| on a Hilbert space H$ is order inclusion transitive on $C C(H)$ if given any $A, B \in C C(H)$ with $A \subseteq B$ and arbitrary $x \in H$, then $d(x, B)=\inf _{\bar{b} \in B} \| \bar{b}-$ $x\|=\| b-x \|$ and $d(b, A)=\inf _{\bar{a} \in A}\|\bar{a}-b\|=\|a-b\|$ imply that $d(x, A)=\inf _{\bar{a} \in A}\|\bar{a}-x\|=\|a-x\|$ and $E P(F)$ is the set of the solutions of the equilibrium problem for the bifunction. Also if we set $y_{n}=\alpha_{n} x_{n}+\left(1-\alpha_{n}\right) v_{n}$ in Algorithm 1, where $\left\{\alpha_{n}\right\}_{n=1}^{\infty} \subset$ $[0,1]$ satisfying some conditions and $T: K \longrightarrow P(K)$ is a multivalued $k$-strictly pseudocontractive-type mapping a similar selection existing as well which is a selection of Algorithm 2, the numerical example of the computation is presented for the selection of Algorithm 2 which is the generalization of the selections of Algorithm 1. The results of this research are great contributions towards the resolution of the controversy over the computability and applicability of algorithms for approximating the solutions of equilibrium problems for bifunctions involving the construction of the sequences $\left\{K_{n}\right\}_{n=1}^{\infty}$ and $\left\{x_{n}\right\}_{n=1}^{\infty}$ above.

\section{Preliminaries}

Let $X$ be a nonempty set and let $T: X \longrightarrow X$ be a map. A point $x \in X$ is called a fixed point of $T$ if $x=T x$. If $T: X \longrightarrow$ $2^{X}$ is a multivalued map from $X$ into the family of nonempty subsets of $X$, then $x$ is a fixed point of $T$ if $x \in T x$. If $T x=\{x\}$, $x$ is called a strict fixed point of $T$. The set $F(T)=\{x \in D(T)$ : $x \in T x\}$ (respectively, $F(T)=\{x \in D(T): x=T x\}$ ) is called the fixed point set of multivalued (respectively, single-valued) map $T$ while the set $F_{s}(T)=\{x \in D(T): T x=\{x\}\}$ is called the strict fixed point set of $T$.

Let $X$ be a normed space. A subset $K$ of $X$ is called proximinal if for each $x \in X$ there exists $k \in K$ such that

$$
\|x-k\|=\inf \{\|x-y\|: y \in K\}=d(x, K) .
$$

It is known that every closed convex subset of a uniformly convex Banach space is proximinal. We shall denote the family of all nonempty closed and bounded subsets of $X$ by $C B(X)$, the family of all nonempty subsets of $X$ by $2^{X}$, the family of all nonempty closed and convex subsets of $X$ by 
$C C(X)$, and the family of all proximinal subsets of $X$ by $P(X)$, for a nonempty set $X$.

Let $H$ denote the Hausdorff metric induced by the metric $d$ on $X$; that is, for every $A, B \in C B(X)$,

$$
H(A, B)=\max \left\{\sup _{a \in A} d(a, B), \sup _{b \in B} d(b, A)\right\} .
$$

Let $X$ be a normed space. Let $T: D(T) \subseteq X \longrightarrow 2^{X}$ be a multivalued mapping on $X$. A multivalued mapping $T$ : $D(T) \subseteq X \longrightarrow 2^{X}$ is called $L-$ Lipschitzian if there exists $L \geq 0$ such that for all $x, y \in D(T)$

$$
H(T x, T y) \leq L\|x-y\| .
$$

In (7), if $L \in[0,1) T$ is said to be a contraction while $T$ is nonexpansive if $L=1$.

Definitions 3 (see [11]). $T$ is said to be $k$-strictly pseudocontractive-type of Isiogugu [11] if there exists $k \in(0,1)$ such that given any pair $x, y \in D(T)$ and $u \in T x$, there exists $v \in T y$ satisfying $\|u-v\| \leq H(T x, T y)$ and

$$
H^{2}(T x, T y) \leq\|x-y\|^{2}+k\|x-u-(y-v)\|^{2} .
$$

Definitions 4. A multivalued map $T: D(T) \subseteq X \longrightarrow 2^{X}$ is said to be of type-one (see for example $[12,13])$ if given any pair $x, y \in D(T)$, then

$$
\|u-v\| \leq H(T x, T y), \quad \text { for all } u \in P_{T} x, v \in P_{T} y .
$$

Lemma 5 (see [14]). Let $H$ be a real Hilbert space and let $T: D(T) \subseteq H \longrightarrow 2^{H}$ be a $k$-strictly pseudocontractive-type mapping. Then $T$ is an L-Lipschitzian.

Lemma 6 (see [7]). Let $K$ be a nonempty subset of a real Hilbert space $H$ and let $T: K \longrightarrow P(K)$ be a $k$-strictly pseudocontractive-type mapping such that $F_{s}(T)$ is nonempty. Then $F_{s}(T)$ is closed and convex.

Lemma 7. Let $H$ be a real Hilbert space and let $K$ be a nonempty closed convex subset of $H$. Let $P_{K}$ be the convex projection onto $K$. Then, convex projection is characterized by the following relations:

(i) $x^{*}=P_{K}(x) \Longleftrightarrow\left\langle x-x^{*}, y-x^{*}\right\rangle \leq 0$, for all $y \in K$.

(ii) $\left\|x-P_{K} x\right\|^{2} \leq\|x-y\|^{2}-\left\|y-P_{K} x\right\|^{2}$.

(iii) $\left\|x-P_{K} y\right\|^{2} \leq\|x-y\|^{2}-\left\|P_{K} y-y\right\|^{2}$.

Lemma 8 (see [1]). Let $K$ be a nonempty closed convex subset of a real Hilbert space $H$ and $F: K \times K \longrightarrow \mathbb{R}$ a bifunction satisfying (A1)-(A4). Let $r>0$ and $x \in H$. Then, there exists $z \in K$ such that

$$
F(z, y)+\frac{1}{r}\langle y-z, z-x\rangle \geq 0, \quad \forall y \in K .
$$

Lemma 9 (see [2]). Let $K$ be a nonempty closed convex subset of a real Hilbert space $H$. Assume that $F: K \times K \longrightarrow \mathbb{R}$ satisfies (A1)-(A4). Let $r>0$ and $x \in H$; define $T_{r}: H \longrightarrow 2^{K}$ by

$$
T_{r}(x)=\left\{z \in K: F(z, y)+\frac{1}{r}\langle y-z, z-x\rangle \geq 0\right\},
$$

Then the following conditions hold:

(1) $T_{r}$ is single-valued.

(2) $T_{r}$ is firmly nonexpansive, that is for any $x, y \in H$, $\left\|T_{r} x-T_{r} y\right\|^{2} \leq\left\langle T_{r} x-T_{r} y, x-y\right\rangle$.

(3) $F\left(T_{r}\right)=E P(F)$.

(4) $E P(F)$ is closed and convex.

Lemma 10 (see [15]). Let $K$ be a nonempty closed convex subset of a real Hilbert space $H$ and $F: K \times K \longrightarrow \mathbb{R} a$ bifunction satisfying (A1)-(A4). Let $r>0$ and $x \in H$. Then for all $x \in H$ and $p \in F\left(T_{r}\right)$

$$
\left\|p-T_{r} x\right\|^{2}+\left\|T_{r} x-x\right\|^{2} \leq\|p-x\|^{2} .
$$

Definition 11 (see $[16,17])$. Let $E$ be a Banach space. Let $T$ : $D(T) \subseteq E \longrightarrow 2^{E}$ be a multivalued mapping. $I-T$ is said to be weakly demiclosed at zero if for any sequence $\left\{x_{n}\right\}_{n=1}^{\infty} \subseteq$ $D(T)$ such that $\left\{x_{n}\right\}$ converges weakly to $p$ and a sequence $\left\{y_{n}\right\}$ with $y_{n} \in T x_{n}$ for all $n \in \mathbb{N}$ such that $\left\{x_{n}-y_{n}\right\}$ converges strongly to zero. Then $p \in T p$ (i.e., $0 \in(I-T) p)$.

\section{Main Results}

Definition 12. Let $\left\{K_{n}\right\}_{n=1}^{\infty}$ be sequence of sets. Then a sequence $\left\{z_{n}\right\}_{n=1}^{\infty}$ is called a selection of $\left\{K_{n}\right\}_{n=1}^{\infty}$ if $z_{n} \in K_{n}$ for each $n$.

Definition 13. A norm $\|$.$\| on a Hilbert space H$ is order inclusion transitive on $C C(H)$ if given any $A, B \in C C(H)$ with $A \subseteq B$ and arbitrary $x \in H$, then $d(x, B)=\inf _{\bar{b} \in B} \| \bar{b}-$ $x\|=\| b-x \|$ and $d(b, A)=\inf _{\bar{a} \in A}\|\bar{a}-b\|=\|a-b\|$ imply that $d(x, A)=\inf _{\bar{a} \in A}\|\bar{a}-x\|=\|a-x\|$ (i.e., if $b$ is the point in $\mathrm{B}$ closet to $x$ and $a$ is the point in $A$ closest to $b$ then $a$ is the point in $A$ closest to $x$ ).

Definition 14. A Hilbert $H$ is said to have order inclusion transitive property on $C C(H)$ if its norm is order inclusion transitive on $C C(H)$.

It is easy to see that the set of real numbers with the usual norm has order inclusion transitive property.

Proposition 15. In the definition of the set $K_{n+1}:=\left\{z \in K_{n}\right.$ : $\left.\left\|z-u_{n}\right\|^{2} \leq\left\|z-x_{n}\right\|^{2}\right\}$, if we define $x_{n+1}=(1 / 2)\left(u_{n}+x_{n}\right)$, then the following conditions are true:

$\left(C_{1}\right)\left\{x_{n}\right\}_{n=1}^{\infty}$ is a selection of $\left\{K_{n}\right\}_{n=1}^{\infty}$.

$\left(C_{2}\right) x_{n+1}=P_{K_{n+1}} x_{n}$.

$\left(C_{3}\right)$ If $H$ has order inclusion transitive property on $C C(H)$ then, $x_{n+1}=P_{K_{n+1}} x_{0}$

Proof. $\left(C_{1}\right)$

$$
\left\|x_{n+1}-u_{n}\right\|^{2}=\left\|\frac{1}{2}\left(u_{n}+x_{n}\right)-u_{n}\right\|^{2}=\frac{1}{4}\left\|u_{n}-x_{n}\right\|^{2}
$$

and

$$
\left\|x_{n+1}-x_{n}\right\|^{2}=\left\|\frac{1}{2}\left(u_{n}+x_{n}\right)-x_{n}\right\|^{2}=\frac{1}{4}\left\|u_{n}-x_{n}\right\|^{2} .
$$


Therefore, $x_{n+1} \in K_{n+1}$; thus, $\left\{x_{n}\right\}_{n=1}^{\infty}$ is a selection of $\left\{K_{n}\right\}_{n=1}^{\infty}$.

$\left(C_{2}\right)$ Let $y \in K_{n+1}$ arbitrary. Then

$$
\begin{aligned}
&\left\langle x_{n}-x_{n+1}, y-x_{n+1}\right\rangle=\left\langle x_{n}-\frac{1}{2}\left(u_{n}+x_{n}\right), y\right. \\
&\left.-\frac{1}{2}\left(u_{n}+x_{n}\right)\right\rangle=\left\langle\frac{1}{2}\left(x_{n}-u_{n}\right),\right. \\
&\left.-\frac{1}{2}\left(\left(u_{n}-y\right)+\left(x_{n}-y\right)\right)\right\rangle=\frac{1}{4}\left\langle x_{n}-u_{n},\right. \\
&\left.-\left(u_{n}-y\right)-\left(x_{n}-y\right)\right\rangle=\frac{1}{4}\left\langle\left(x_{n}-y\right)\right. \\
&\left.+\left(y-u_{n}\right),\left(y-u_{n}\right)+\left(y-x_{n}\right)\right\rangle \\
&=\frac{1}{4}\left[\left\langle x_{n}-y, y-u_{n}\right\rangle+\left\langle x_{n}-y, y-x_{n}\right\rangle\right. \\
&\left.+\left\langle y-u_{n}, y-u_{n}\right\rangle+\left\langle y-u_{n}, y-x_{n}\right\rangle\right] \\
&=\frac{1}{4}\left[\left\langle x_{n}-y, y-u_{n}\right\rangle-\left\langle y-x_{n}, y-x_{n}\right\rangle\right. \\
&\left.+\left\langle y-u_{n}, y-u_{n}\right\rangle+\left\langle y-u_{n}, y-x_{n}\right\rangle\right] \\
&+ \\
&+\frac{1}{4}\left[\left\langle x_{n}-y, y-u_{n}\right\rangle-\left\|y-x_{n}\right\|^{2}+\left\|y-u_{n}\right\|^{2}\right. \\
&+\left.\left\langle y-u_{n}, y-x_{n}\right\rangle\right]=\frac{1}{4}\left[-\left\langle y-x_{n}, y-u_{n}\right\rangle\right. \\
&\left.+x_{n}\left\|^{2}+\right\| y-u_{n} \|^{2}+\left\langle y-x_{n}, y-u_{n}\right\rangle\right] \\
&\left.\left\langle y-x_{n}, y-u_{n}\right\rangle\right]=0 . \\
& \\
&
\end{aligned}
$$

Consequently, $x_{n+1}=P_{K_{n+1}} x_{n}$.

$\left(\mathrm{C}_{3}\right)$ Since $K_{n+1} \subseteq K_{n}$ and $K_{n}$ is closed and convex for each n, condition $C_{2}$ and order inclusion transitive property of $H$ on $C C(H)$ guarantee that $x_{n+1}=P_{K_{n+1}} x_{0}$.

We now consider the following algorithm which we shall refer to as a selection of Algorithm 1 .

Let $H$ be a real Hilbert space, $K$ be a nonempty closed convex subset of $H$, and $F: K \times K \longrightarrow \mathbb{R}$ be a bifunction. Let $r \in[a, \infty)$ for some $a>0$. Then from an arbitrary $x_{0} \in H$ we generate the sequence $\left\{x_{n}\right\}_{n=1}^{\infty}$ as follows.

\section{Algorithm 16.}

$$
\begin{aligned}
y_{n} & =x_{n}, \\
u_{n} & \in K \text { such that } F\left(u_{n}, y\right)+\frac{1}{r}\left\langle y-u_{n}, u_{n}-y_{n}\right\rangle \\
& \geq 0, \quad \forall y \in K, \\
x_{n+1} & =\frac{1}{2}\left(u_{n}+x_{n}\right) .
\end{aligned}
$$

Theorem 17. Let $H,\left\{x_{n}\right\}_{n=1}^{\infty}$ and $F$ and $r$ be as in Algorithm 16. Suppose $F$ satisfying (A1)-(A4), EP(F) $\neq \emptyset$, then (i) $\left\{x_{n}\right\}$ converges strongly to $p \in E P(F)$; (ii) if $H$ has order inclusion transitive property, then $\left\{x_{n}\right\}_{n=1}^{\infty}$ converges strongly to $P_{E P(F)} x_{0}$.

Proof. Since $u_{n}=T_{r} y_{n}=T_{r} x_{n}$, given arbitrary $q \in E P(F)$, we have that

$$
\begin{aligned}
\left\|x_{n+1}-q\right\|^{2}= & \left\|\frac{1}{2}\left(u_{n}+x_{n}\right)-q\right\|^{2} \\
= & \left\|\frac{1}{2}\left(u_{n}-q\right)+\frac{1}{2}\left(x_{n}-q\right)\right\|^{2} \\
= & \frac{1}{2}\left\|u_{n}-q\right\|^{2}+\frac{1}{2}\left\|x_{n}-q\right\|^{2} \\
& -\frac{1}{2}\left\|x_{n}-u_{n}\right\|^{2} \\
\leq & \frac{1}{2}\left\|x_{n}-q\right\|^{2}+\frac{1}{2}\left\|x_{n}-q\right\|^{2} \\
& -\frac{1}{4}\left\|x_{n}-u_{n}\right\|^{2} \\
= & \left\|x_{n}-q\right\|^{2}-\frac{1}{4}\left\|x_{n}-u_{n}\right\|^{2} \leq\left\|x_{n}-q\right\|^{2} .
\end{aligned}
$$

Therefore, $\left\{\left\|x_{n}-p\right\|\right\}_{n=0}^{\infty}$ is monotone, nonincreasing, and bounded; hence, $\lim _{n \rightarrow \infty}\left\|x_{n}-q\right\|$ exists. Also,

$$
\frac{1}{4}\left\|x_{n}-u_{n}\right\|^{2} \leq\left\|x_{n}-q\right\|^{2}-\left\|x_{n+1}-q\right\|^{2} .
$$

Hence $\sum_{n=0}^{\infty}\left\|x_{n}-u_{n}\right\|^{2}<\infty$ which implies that $\lim _{n \rightarrow \infty} \| x_{n}-$ $u_{n}\|=\| x_{n}-T_{r} x_{n} \|=0$. Also,

$$
\left\|x_{n+1}-x_{n}\right\|=\frac{1}{2}\left\|x_{n}-u_{n}\right\| \leq\left\|x_{n}-u_{n}\right\|,
$$

so that $\lim _{n \rightarrow \infty}\left\|x_{n+1}-x_{n}\right\|=0$. Consequently $\left\{x_{n}\right\}_{n=0}^{\infty}$, $\left\{y_{n}\right\}_{n=0}^{\infty}=\left\{x_{n}\right\}_{n=0}^{\infty}$, and $\left\{u_{n}\right\}_{n=0}^{\infty}=\left\{T_{r} x_{n}\right\}_{n=0}^{\infty}$ are bounded. From $\lim _{n \longrightarrow \infty}\left\|x_{n+1}-x_{n}\right\|=0$ we have that $\left\{x_{n}\right\}_{n=0}^{\infty}$ is a Cauchy in $K$ and hence converges strongly to $p \in K$. From the Opial condition of $H$, the firmly nonexpansive and demiclosedness property of $\left(I-T_{r}\right)$ established that $p \in F\left(T_{r}\right)=E P(F)$. (ii) If $H$ has order inclusion transitive property then $x_{n}=P_{K_{n}} x_{0}$, consequently, from Lemma 7(i)

$$
\left\langle x_{n}-y, x_{0}-x_{n}\right\rangle \geq 0, \quad \forall y \in K_{n} .
$$

Since $E P(F) \subseteq K_{n}$ for all $n \geq 1$, we have that

$$
\left\langle x_{n}-q, x_{0}-x_{n}\right\rangle \geq 0, \quad \forall q \in E P(F) .
$$

Taking the limit as $n \longrightarrow \infty$ in (21) we have

$$
\left\langle p-q, x_{0}-p\right\rangle \geq 0, \quad \forall q \in E P(F) .
$$

Thus, from Lemma 7(i) $p=P_{E P(F)} x_{0}$. This completes the proof.

Remark 18. It is important to note that the strong convergence of Algorithm 16 to a $p \in E P(F)$ does not depend on the order inclusion transitive property condition on $H$. 
Motivated by Algorithm 16 we now obtain the following algorithm which is a selection of Algorithm 2.

Let $H$ be a real Hilbert space, $K$ be a closed and convex subset of $H, F: K \times K \longrightarrow \mathbb{R}$ be a bifunction, and $T:$ $K \longrightarrow P(K)$ be a multivalued $k$-strictly pseudocontractivetype mapping. Let $\left\{\alpha_{n}\right\}_{n=1}^{\infty} \subset[0,1]$ and $r_{n} \in[a, \infty)$ for some $a>0$. Then from an arbitrary $x_{0} \in H$ the algorithm is generated as follows.

\section{Algorithm 19.}

$$
\begin{aligned}
y_{n} & =\alpha_{n} x_{n}+\left(1-\alpha_{n}\right) v_{n}, \\
u_{n} & \in K \text { such that } F\left(u_{n}, y\right)+\frac{1}{r_{n}}\left\langle y-u_{n}, u_{n}-y_{n}\right\rangle \\
& \geq 0, \quad \forall y \in K, \\
x_{n+1} & =\frac{1}{2}\left(u_{n}+x_{n}\right),
\end{aligned}
$$

where $v_{n} \in T x_{n}$.

Theorem 20. Let $H, K, F, T,\left\{\alpha_{n}\right\}$, and $\left\{r_{n}\right\}$ be as in Algorithm 19. Suppose that (I-T) is weakly demiclosed at zero, $F$ satisfies (A1)-(A4), $\mathbb{F}=F_{s}(T) \cap E P(F) \neq \emptyset$, and $\left\{\alpha_{n}\right\}$ satisfies (i) $\alpha_{n} \longrightarrow \alpha<1-k$; (ii) $\alpha>0$; (iii) $\sum_{n=1}^{\infty} \alpha_{n}\left(1-\alpha_{n}\right)=\infty$. Then $\left\{x_{n}\right\}$ converges strongly to $q \in \mathbb{F}$. Also, if $H$ has order inclusion transitive property, then $q=P_{\mathbb{F}} x_{0}$.

Proof. Let $p \in \mathbb{F}$ be arbitrary. Then

$$
\begin{aligned}
& \left\|x_{n+1}-p\right\|^{2}=\left\|\frac{1}{2}\left(x_{n}+u_{n}\right)-p\right\|^{2}=\frac{1}{2}\left\|x_{n}-p\right\|^{2} \\
& +\frac{1}{2}\left\|u_{n}-p\right\|^{2}-\frac{1}{4}\left\|x_{n}-u_{n}\right\|^{2} \leq \frac{1}{2}\left\|x_{n}-p\right\|^{2} \\
& +\frac{1}{2}\left\|y_{n}-p\right\|^{2}-\frac{1}{4}\left\|x_{n}-u_{n}\right\|^{2}=\frac{1}{2}\left\|x_{n}-p\right\|^{2} \\
& -\frac{1}{4}\left\|x_{n}-u_{n}\right\|^{2}+\frac{1}{2}\left\|\left(1-\alpha_{n}\right) x_{n}+\alpha_{n} v_{n}-p\right\|^{2} \\
& \quad=\frac{1}{2}\left\|x_{n}-p\right\|^{2}-\frac{1}{4}\left\|x_{n}-u_{n}\right\|^{2} \\
& +\frac{1}{2}\left[\left\|\left(1-\alpha_{n}\right)\left(x_{n}-p\right)+\alpha_{n}\left(v_{n}-p\right)\right\|^{2}\right]=\frac{1}{2} \| x_{n} \\
& -p\left\|^{2}-\frac{1}{4}\right\| x_{n}-u_{n} \|^{2}+\frac{1}{2}\left[\left(1-\alpha_{n}\right)\left\|x_{n}-p\right\|^{2}\right. \\
& \left.+\alpha_{n}\left\|v_{n}-p\right\|^{2}-\alpha_{n}\left(1-\alpha_{n}\right)\left\|x_{n}-v_{n}\right\|^{2}\right] \leq \frac{1}{2} \| x_{n} \\
& \quad-p\left\|^{2}-\frac{1}{4}\right\| x_{n}-u_{n} \|^{2}+\frac{1}{2}\left[\left(1-\alpha_{n}\right)\left\|x_{n}-p\right\|^{2}\right. \\
& \left.+\alpha_{n} H^{2}\left(T x_{n}, T p\right)-\alpha_{n}\left(1-\alpha_{n}\right)\left\|x_{n}-v_{n}\right\|^{2}\right] \\
& \quad \leq \frac{1}{2}\left\|x_{n}-p\right\|^{2}-\frac{1}{4}\left\|x_{n}-u_{n}\right\|^{2}
\end{aligned}
$$

$$
\begin{aligned}
& +\frac{1}{2}\left[\left(1-\alpha_{n}\right)\left\|x_{n}-p\right\|^{2}\right. \\
& +\alpha_{n}\left[\left\|x_{n}-p\right\|^{2}+k\left\|x_{n}-v_{n}\right\|^{2}\right] \\
& \left.-\alpha_{n}\left(1-\alpha_{n}\right)\left\|x_{n}-v_{n}\right\|^{2}\right]=\frac{1}{2}\left\|x_{n}-p\right\|^{2}-\frac{1}{4} \| x_{n} \\
& -u_{n} \|^{2}+\frac{1}{2}\left[\left\|x_{n}-p\right\|^{2}\right. \\
& \left.-\alpha_{n}\left(1-\left(\alpha_{n}+k\right)\right)\left\|x_{n}-v_{n}\right\|^{2}\right]=-\frac{1}{4}\left\|x_{n}-u_{n}\right\|^{2} \\
& +\left\|x_{n}-p\right\|^{2}-\frac{1}{2} \alpha_{n}\left(1-\left(\alpha_{n}+k\right)\right)\left\|x_{n}-v_{n}\right\|^{2} .
\end{aligned}
$$

It then follows that $\lim _{n \rightarrow \infty}\left\|x_{n}-p\right\|$ exists; hence, $\left\{x_{n}\right\}$ is bounded. Also,

$$
\sum_{n=1}^{\infty} \frac{1}{2} \alpha_{n}\left(1-\left(\alpha_{n}+k\right)\right)\left\|x_{n}-v_{n}\right\|^{2} \leq\left\|x_{0}-p\right\|^{2}<\infty
$$

Since $\alpha>0$ from (ii), we have that $\lim _{n \rightarrow \infty}\left\|x_{n}-v_{n}\right\|=$ 0 . Furthermore, $\lim _{n \rightarrow \infty}\left\|x_{n}-u_{n}\right\|=0$. Consequently, $\lim _{n \rightarrow \infty}\left\|x_{n+1}-x_{n}\right\|^{2}=\lim _{n \rightarrow \infty}\left\|(1 / 2)\left(x_{n}-u_{n}\right)\right\|^{2}=0$ which implies that $\left\{x_{n}\right\}$ is a Cauchy sequence in $K$. Also, since $K$ is closed and convex, $\left\{x_{n}\right\}$ converges strongly to some $q \in K$. From the Opial condition of $H$, weakly demiclosed of $(I-T)$ at zero, we have that $q \in T q$.

It remains to show that $q$ is in $E P(F)$ since

$$
\lim _{n \longrightarrow \infty}\left\|x_{n}-u_{n}\right\|=0 .
$$

It follows from $\lim _{n \rightarrow \infty}\left\|x_{n}-q\right\|=0$ and (26) that

$$
\lim _{n \longrightarrow \infty}\left\|u_{n}-q\right\|=0 .
$$

Also,

$$
\left\|y_{n}-q\right\|^{2} \leq\left\|x_{n}-q\right\|^{2}-\alpha_{n}\left(1-\left(\alpha_{n}+k\right)\right)\left\|x_{n}-v_{n}\right\|^{2} .
$$

Observe that

$$
\begin{aligned}
\| q & -x_{n}\left\|^{2}-\right\| q-u_{n} \|^{2} \\
& =\left\|x_{n}\right\|^{2}-\left\|u_{n}\right\|^{2}-2\left\langle q, x_{n}-u_{n}\right\rangle \\
& \leq\left\|x_{n}-u_{n}\right\|\left(\left\|x_{n}\right\|+\left\|u_{n}\right\|\right)+2\|q\|\left\|x_{n}-u_{n}\right\| .
\end{aligned}
$$

It follows from (26) that

$$
\lim _{n \longrightarrow \infty}\left\|q-x_{n}\right\|-\left\|q-u_{n}\right\|=0 .
$$

Now from (28),

$$
\left\|q-y_{n}\right\| \leq\left\|q-x_{n}\right\| .
$$


Also, using $u_{n}=T_{r_{n}} y_{n}$, Lemma 10, and (31) we have

$$
\begin{aligned}
\left\|u_{n}-y_{n}\right\|^{2} & =\left\|T_{r_{n}} y_{n}-y_{n}\right\|^{2} \\
& \leq\left\|q-y_{n}\right\|^{2}-\left\|q-T_{r_{n}} y_{n}\right\|^{2} \\
& \leq\left\|q-x_{n}\right\|^{2}-\left\|q-T_{r_{n}} y_{n}\right\|^{2} \\
& =\left\|q-x_{n}\right\|^{2}-\left\|q-u_{n}\right\|^{2} .
\end{aligned}
$$

Therefore, from (30) and (32),

$$
\lim _{n \longrightarrow \infty}\left\|u_{n}-y_{n}\right\|=0 .
$$

Consequently, from (27) and (33),

$$
\lim _{n \rightarrow \infty}\left\|y_{n}-q\right\|=0 \text {. }
$$

From the assumption that $r_{n} \geq a>0$,

$$
\lim _{n \rightarrow \infty} \frac{\left\|u_{n}-y_{n}\right\|}{r_{n}}=0 .
$$

Since $u_{n}=T_{r_{n}} y_{n}$, we have

$$
F\left(u_{n}, y\right)+\frac{1}{r_{n}}\left\langle y-u_{n}, u_{n}-y_{n}\right\rangle \geq 0 .
$$

We then deduce from (A2) that

$$
\begin{aligned}
\frac{\left\|u_{n}-y_{n}\right\|^{2}}{r_{n}} & \geq \frac{1}{r_{n}}\left\langle y-u_{n}, u_{n}-y_{n}\right\rangle \geq-F\left(u_{n}, y\right) \\
& \geq F\left(y, u_{n}\right), \quad \forall y \in K .
\end{aligned}
$$

By taking limit as $n \longrightarrow \infty$ of the above inequality and from (A4), (27), and (34), $F(y, q) \leq 0$, for all $y \in K$. Let $t \in(0,1)$ and for all $y \in K$, since $q \in K, y_{t}=t y+(1-t) q \in K$. Hence $F\left(y_{t}, q\right) \leq 0$. Therefore, from (A1),

$$
\begin{aligned}
0 & =F\left(y_{t}, y_{t}\right) \leq t F\left(y_{t}, y\right)+(1-t) F\left(y_{t}, q\right) \\
& \leq t F\left(y_{t}, y\right)
\end{aligned}
$$

that is, $F\left(y_{t}, y\right) \geq 0$. Letting $t \downarrow 0$, from (A3) we obtain $F(q, y) \geq 0$ for all $y \in K$ so that $q \in E P(F)$ for all $i=$ $1,2, \ldots, N$. Hence $q \in \mathbb{F}$.

Finally, if $H$ has order inclusion transitive property, $x_{n}=$ $P_{K_{n}} x_{0}$ consequently, from Lemma 7(i)

$$
\left\langle x_{n}-y, x_{0}-x_{n}\right\rangle \geq 0, \quad \forall y \in K_{n} .
$$

Since $E P(F) \subseteq K_{n}$ for all $n \geq 1$, we have that

$$
\left\langle x_{n}-p, x_{0}-x_{n}\right\rangle \geq 0, \quad \forall p \in E P(F) .
$$

Taking the limit as $n \longrightarrow \infty$ in (40) we have

$$
\left\langle q-p, x_{0}-q\right\rangle \geq 0, \quad \forall p \in E P(F) .
$$

Thus, from Lemma 7(i) $q=P_{E P(F)} x_{0}$. This completes the proof.
Remark 21. The above proof shows that the strong convergence of Algorithm 19 to a common solution $q \in \mathbb{F}$ does not depend on order inclusion transitive property condition on $H$. However, order inclusion transitive property is only required on $H$ if we want to have that $p=P_{E P(F)} x_{0}$.

Remark 22. It is also of a great interest to us to get the same results in normed spaces which enjoy the order inclusion transitive property.

\section{Numerical Examples of the Computations}

We shall use Algorithm 19 to recompute the example presented by Isiogugu et al. [13], when $i=1$ is defined as follows.

Let $H=\mathbb{R}$ (the reals with the usual metric and inner product) and $K=[-4,10]$; we define

(i) $T:[-4,10] \longrightarrow P([-4,10])$ by

$$
T x= \begin{cases}{\left[-2 x,-\frac{9 x}{4}\right],} & x \in[-4,0] \\ \left\{-\frac{3 x}{9}\right\}, & x \in(0,10]\end{cases}
$$

We have that, for any $x, y \in[-4,0]$,

$$
\begin{aligned}
H^{2}(T x, T y) & =\left\|\frac{9}{4}(x-y)\right\|^{2}=\left(\frac{9}{4}\right)^{2}\|x-y\|^{2} \\
& =\|x-y\|^{2}+\left(\left(\frac{9}{4}\right)^{2}-1\right)\|x-y\|^{2} .
\end{aligned}
$$

Also, given any $u \in T x, u=-\alpha x, 2 \leq \alpha \leq 9 / 4$, and we can choose $v=-\alpha y \in T y$ so that

$$
\|x-u-(y-v)\|^{2}=(1+\alpha)^{2}\|x-y\|^{2} .
$$

It then follows that

$$
\begin{aligned}
H^{2}(T x, T y)= & \|x-y\|^{2} \\
& +\frac{(9)^{2}-16}{16(1+\alpha)^{2}}\|x-u-(y-v)\|^{2} \\
\leq & \|x-y\|^{2} \\
& +\frac{(9)^{2}-16}{16(1+2)^{2}}\|x-u-(y-v)\|^{2} .
\end{aligned}
$$

Similarly, for any $x \in[-4,0], y \in(0,10]$,

$$
\begin{aligned}
H^{2}(T x, T y)= & \left\|\frac{9}{4} x-\frac{3 y}{9}\right\|^{2} \leq\left\|\frac{9}{4} x-\frac{9}{4} y\right\|^{2} \\
\leq & \|x-y\|^{2} \\
& +\frac{(9)^{2}-16}{16(1+2)^{2}}\|x-u-(y-v)\|^{2} .
\end{aligned}
$$


TABLE 1: Sequences generated by Algorithms 2 and 19.

\begin{tabular}{|c|c|c|c|c|c|c|}
\hline & Algorithm 2 & Algorithm 2 & Algorithm 4 & Algorithm 2 & Algorithm 2 & Algorithm 4 \\
\hline $\mathrm{n}$ & K_n & x_n & X_n & K_n & x_n & X_n \\
\hline 0 & {$[-4,10]$} & 2 & 2 & {$[-4,10]$} & -3 & -3 \\
\hline 1 & {$[-4,1.126855044]$} & 1.126855044 & 1.126855044 & {$[-1.532563756,10]$} & -1.532563756 & -1.532563756 \\
\hline 2 & {$[-4,0.652769535]$} & 0.652769535 & 0.652769535 & {$[-0.787076007,10]$} & -0.787076007 & -0.787076007 \\
\hline 3 & {$[-4,0.38284414]$} & 0.38284414 & 0.38284414 & {$[-0.405188015,10]$} & -0.405188015 & -0.405188015 \\
\hline 4 & {$[-4,0.226111845]$} & 0.226111845 & 0.226111845 & {$[-0.208877029,10]$} & -0.208877029 & -0.208877029 \\
\hline 5 & {$[-4,0.134146663]$} & 0.134146663 & 0.134146663 & {$[-0.107772707,10]$} & -0.107772707 & -0.107772707 \\
\hline 6 & {$[-4,0.079836206]$} & 0.079836206 & 0.079836206 & {$[-0.055641074,10]$} & -0.055641074 & -0.055641074 \\
\hline 7 & {$[-4,0.047623897]$} & 0.047623897 & 0.047623897 & {$[-0.028739594,10]$} & -0.028739594 & -0.028739594 \\
\hline 8 & {$[-4,0.028459121]$} & 0.028459121 & 0.028459121 & {$[-0.014849721,10]$} & -0.014849721 & -0.014849721 \\
\hline 9 & {$[-4,0.01703056]$} & 0.01703056 & 0.01703056 & {$[-0.007674974,10]$} & -0.007674974 & -0.007674974 \\
\hline 10 & {$[-4,0.010203099]$} & 0.010203099 & 0.010203099 & {$[-0.003967653,10]$} & -0.003967653 & -0.003967653 \\
\hline 11 & {$[-4,0.006118509]$} & 0.006118509 & 0.006118509 & {$[-0.002051501,10]$} & -0.002051501 & -0.002051501 \\
\hline 12 & {$[-4,0.003672014]$} & 0.003672014 & 0.003672014 & {$[-0.001060909,10]$} & -0.001060909 & -0.001060909 \\
\hline 13 & {$[-4,0.002205248]$} & 0.002205248 & 0.002205248 & {$[-0.00054871,10]$} & -0.00054871 & -0.00054871 \\
\hline 14 & {$[-4,0.001325149]$} & 0.001325149 & 0.001325149 & {$[-0.00028383,10]$} & -0.00028383 & -0.00028383 \\
\hline 15 & {$[-4,0.000796697]$} & 0.000796697 & 0.000796697 & {$[-0.000146831,10]$} & -0.000146831 & -0.000146831 \\
\hline 16 & {$[-4,0.0004792]$} & 0.0004792 & 0.0004792 & {$[-0.000075965,10]$} & -0.000075965 & -0.000075965 \\
\hline 17 & {$[-4,0.000288345]$} & 0.000288345 & 0.000288345 & {$[-0.000039304,10]$} & -0.000039304 & -0.000039304 \\
\hline 18 & {$[-4,0.000173565]$} & 0.000173565 & 0.000173565 & {$[-0.000020337,10]$} & -0.000020337 & -0.000020337 \\
\hline 19 & {$[-4,0.000104508]$} & 0.000104508 & 0.000104508 & {$[-0.000010523,10]$} & -0.000010523 & -0.000010523 \\
\hline 20 & {$[-4,0.000062945]$} & 0.000062945 & 0.000062945 & {$[-0.000005445,10]$} & -0.000005445 & -0.000005445 \\
\hline 21 & {$[-4,0.000037921]$} & 0.000037921 & 0.000037921 & {$[-0.000002817,10]$} & -0.000002817 & -0.000002817 \\
\hline 22 & {$[-4,0.000022851]$} & 0.000022851 & 0.000022851 & {$[-0.000001457,10]$} & -0.000001457 & -0.000001457 \\
\hline 23 & {$[-4,0.000013772]$} & 0.000013772 & 0.000013772 & {$[-0.000000754,10]$} & -0.000000754 & -0.000000754 \\
\hline 24 & {$[-4,0.000008302]$} & 0.000008302 & 0.000008302 & {$[-0.00000039,10]$} & -0.00000039 & -0.00000039 \\
\hline 25 & {$[-4,0.000005005]$} & 0.000005005 & 0.000005005 & {$[-0.000000201,10]$} & -0.000000201 & -0.000000201 \\
\hline 26 & {$[-4,0.000003018]$} & 0.000003018 & 0.000003018 & {$[-0.000000103,10]$} & -0.000000103 & -0.000000103 \\
\hline 27 & {$[-4,0.00000182]$} & 0.00000182 & 0.00000182 & {$[-0.000000053,10]$} & -0.000000053 & -0.000000053 \\
\hline 28 & {$[-4,0.000001097]$} & 0.000001097 & 0.000001097 & {$[-0.000000027,10]$} & -0.000000027 & -0.000000027 \\
\hline 29 & {$[-4,0.000000661]$} & 0.000000661 & 0.000000661 & {$[-0.000000013,10]$} & -0.000000013 & -0.000000013 \\
\hline 30 & {$[-4,0.000000398]$} & 0.000000398 & 0.000000398 & {$[-0.000000006,10]$} & -0.000000006 & -0.000000006 \\
\hline 31 & {$[-4,0.00000024]$} & 0.00000024 & 0.00000024 & {$[-0.000000003,10]$} & -0.000000003 & -0.000000003 \\
\hline 32 & {$[-4,0.000000144]$} & 0.000000144 & 0.000000144 & {$[-0.000000001,10]$} & -0.000000001 & -0.000000001 \\
\hline 33 & {$[-4,0.000000086]$} & 0.000000086 & 0.000000086 & $\{0\}$ & 0 & 0 \\
\hline 34 & {$[-4,0.000000051]$} & 0.000000051 & 0.000000051 & & & \\
\hline 35 & {$[-4,0.00000003]$} & 0.00000003 & 0.00000003 & & & \\
\hline 36 & {$[-4,0.000000018]$} & 0.000000018 & 0.000000018 & & & \\
\hline 37 & {$[-4,0.00000001]$} & 0.00000001 & 0.00000001 & & & \\
\hline 38 & {$[-4,0.000000005]$} & 0.000000005 & 0.000000005 & & & \\
\hline 39 & {$[-4,0.000000002]$} & 0.000000002 & 0.000000002 & & & \\
\hline 40 & {$[-4,0.000000001]$} & 0.000000001 & 0.000000001 & & & \\
\hline 41 & $\{0\}$ & 0 & 0 & & & \\
\hline
\end{tabular}


Furthermore, for any $x, y \in(0,10]$,

$$
\begin{aligned}
H^{2}(T x, T y)= & \frac{3}{9}\|x-y\|^{2} \\
\leq & \|x-y\|^{2} \\
& +\frac{(9)^{2}-16}{16(1+2)^{2}}\|x-u-(y-v)\|^{2} .
\end{aligned}
$$

Thus, $T$ is $\left((9)^{2}-16\right) / 16(1+2)^{2}$-strictly pseudocontractivetype. It is easy to see that, given any pair $x, y \in[-4,0]$, we have that $H(T x, T y)=(9 / 4)\|x-y\|$. Therefore $T$ is not nonexpansive and $F_{s}(T)=\{0\} \neq \emptyset$. We then set

(ii)

$$
v_{n}= \begin{cases}-\frac{9 x_{n}}{4}, & x_{n} \in[-4,0] \\ -\frac{3 x_{n}}{9}, & x_{n} \in(0,10] .\end{cases}
$$

(iii)

$$
\begin{aligned}
& \left\{\alpha_{n}\right\}_{n=1}^{\infty} \\
& =\frac{\left((9)^{2}-16+16(1+2)^{2}\right)\left(n+32(1+2)^{2}\right)^{2}+32(1+2)^{2}}{32(1+2)^{2}\left(n+32(1+2)^{2}\right)^{2}} .
\end{aligned}
$$

We also let $F: R \times R \longrightarrow R,\left\{r_{n}\right\}_{n=1}^{\infty}$, and $\left\{u_{n}\right\}_{n=1}^{\infty}$ to be as defined in [9] for $i=1$. That is,

(iv) $F(x, y)=-x^{2}+y^{2}$.

Observe that $E P(F)=\{0\}, F_{s}(T) \cap E P(F)=\{0\}$, and

$$
\begin{aligned}
& F(z, y)+\frac{1}{r}\langle y-z, z-x\rangle \geq 0 \\
& \Longrightarrow y^{2}-z^{2}+\frac{1}{r}(y-z)(z-x) \geq 0, \\
& \Longrightarrow y^{2}-z^{2}+\frac{1}{r}\left[y z-x y-z^{2}+x z\right] \geq 0, \\
& \Longrightarrow r y^{2}-r z^{2}+y z-x y-z^{2}+x z \geq 0, \\
& \Longrightarrow r y^{2}+(z-x) y-r z^{2}-z^{2}+x z \geq 0 .
\end{aligned}
$$

Now $F(y)=r y^{2}+(z-x) y-r z^{2}-z^{2}+x z$ is a quadratic function of $y$ with coefficients $a=r, b=z-x$, and $c=-r z^{2}-z^{2}+x z$. Therefore, we can compute the discriminant $\Delta$ of $F$ as follows:

$$
\begin{aligned}
\Delta & =(z-x)^{2}+4 r\left(r z^{2}+z^{2}-x z\right) \\
& =z^{2}+x^{2}-2 x z+4 r^{2} z^{2}+4 r z^{2}-4 r x z \\
& =\left(1+4 r^{2}+4 r\right) z^{2}-2(2 r+1) x z+x^{2} \\
& =(1+2 r)^{2} z^{2}-2(1+2 r) x z+x^{2} \\
& =[(1+2 r) z-x]^{2} .
\end{aligned}
$$

Obviously, $F(y) \geq 0$ for all $y \in \mathbb{R}$ if it has at most one solution in $\mathbb{R}$. Thus $\Delta \leq 0$ and hence $z=T_{r_{n}}(x)=x /(1+2 r)$. Consequently, (v) $\left\{u_{n}\right\}_{n=1}^{\infty}=\left\{T_{r_{n}}\left(y_{n}\right)\right\}_{n=1}^{\infty}=\left\{y_{n} /\left(2 r_{n}+1\right)\right\}_{n=1}^{\infty}$,

(vi) $\left\{r_{n}\right\}_{n=1}^{\infty}=\{(n+1) / n\}_{n=1}^{\infty}$.

The algorithm is computed with Microsoft word Excel 972003 Workbook. Table 1 shows the sequences $\left\{x_{n}\right\}$ and $\left\{K_{n}\right\}$ generated from our computation using two different values of $x_{0}=2,-3$.

\section{Disclosure}

Opinions expressed and conclusions arrived are those of the authors and are not necessarily to be attributed to the CoEMaSs.

\section{Conflicts of Interest}

The authors declare that there are no conflicts of interest.

\section{Acknowledgments}

The first author acknowledges with thanks the bursary and financial support from Department of Science and Technology and National Research Foundation, Republic of South Africa Center of Excellence in Mathematical and Statistical Sciences (DST-NRF CoE-MaSS) Postdoctoral Bursary.

\section{References}

[1] E. Blum and W. Oettli, "From optimization and variational inequalities to equilibrium problems," The Mathematics Student, vol. 63, no. 1-4, pp. 123-145, 1994.

[2] P. L. Combettes and S. A. Hirstoaga, "Equilibrium programming in Hilbert spaces," Journal of Nonlinear and Convex Analysis, vol. 6, no. 1, pp. 117-136, 2005.

[3] A. Moudafi, "Second-order differential proximal methods for equilibrium problems," Journal of Inequalities in Pure and Applied Mathematics, vol. 4, no. 1, article 18, 2003.

[4] S. Reich and S. Sabach, "Three strong convergence theorems regarding iterative methods for solving equilibrium problems in reflexive Banach Spaces," Contemporary Mathematics, vol. 568, pp. 225-240, 2012.

[5] F. O. Isiogugu, "Approximation of a Common Element of the Fixed Point Sets of Multivalued Strictly Pseudocontractive-Type Mappings and the Set of Solutions of an Equilibrium Problem in Hilbert Spaces," Abstract and Applied Analysis, vol. 2016, Article ID 3094838, 6 pages, 2016.

[6] A. Tada and W. Takahashi, "Strong convergence theorem for an equilibrium problem and a nonexpansive mapping," in Nonlinear Analysis and Convex Analysis, W. Takahashi and T. Tanaka, Eds., pp. 609-617, 2006.

[7] L.-J. Qin and L. Wang, "An iteration method for solving equilibrium problems, common fixed point problems of strictly pseudocontractive mappings of Browder-Petryshyn type in Hilbert spaces," International Mathematical Forum. Journal for Theory and Applications, vol. 6, no. 1-4, pp. 63-74, 2011.

[8] C. Jaiboon and P. Kumam, "Strong convergence theorems for solving equilibrium problems and fixed point problems of $\xi$ strict pseudo-contraction mappings by two hybrid projection methods," Journal of Computational and Applied Mathematics, vol. 234, no. 3, pp. 722-732, 2010.

[9] F. O. Isiogugu, P. Pillay, C. C. Okeke, and F. U. Ogbuisi, "Modified Reich-Sabach Iteration Scheme for Approximating 
a Common Element of the Solutions of Equilibrium Problems and Fixed Point Problems in Hilbert Spaces," Global Journal of Pure and Applied Mathematics, vol. 12, no. 6, pp. 5185-5204, 2016.

[10] Z. Ma, L. Lin, and C. Hua, "An iterative method for equilibrium problem and fixed point problems of strictly pseudocontractive mappings of Browder-petryshyn type," Nonlinear Functional Analysis and Applications, vol. 6, no. 2, pp. 273-284, 2011.

[11] F. O. Isiogugu, "Demiclosedness principle and approximation theorems for certain classes of multivalued mappings in Hilbert spaces," Fixed Point Theory and Applications, vol. 2013, article 61, 2013.

[12] F. O. Isiogugu, P. Pillay, and M. O. Osilike, "On approximation of fixed points of multi-valued quasi-nonexpansive mappings," Journal of Nonlinear and Convex Analysis. An International Journal, vol. 17, no. 7, pp. 1303-1310, 2016.

[13] F. O. Isiogugu, P. Pillay, C. C. Okeke, F. U. Ogbuisi, and P. U. Nwokoro, "Convergence theorems for modified mann reichsabach iteration scheme for approximating the common solution of equilibrium problems and fixed point problems in hilbert spaces with numerical examples," Communications in Physical Sciences.

[14] F. O. Isiogugu, A. Udomene, and M. O. Osilike, "Approximation of common solutions of equilibrium and fixed point problems for certain classes of mappings," Journal of the Nigerian Mathematical Society, vol. 30, pp. 179-194, 2011.

[15] W. Takahashi and K. Zembayashi, "Strong and weak convergence theorems for equilibruim problems and relatively nonexpansive mappings in Banach spaces," Nonlinear Analysis: Theory, Methods \& Applications, vol. 70, no. 1, pp. 45-57, 2009.

[16] E. Lami Dozo, "Multivalued nonexpansive mappings and Opial's condition," Proceedings of the American Mathematical Society, vol. 38, pp. 286-292, 1973.

[17] J. García-Falset, E. Llorens-Fuster, and T. Suzuki, "Fixed point theory for a class of generalized nonexpansive mappings," Journal of Mathematical Analysis and Applications, vol. 375, no. 1, pp. 185-195, 2011. 


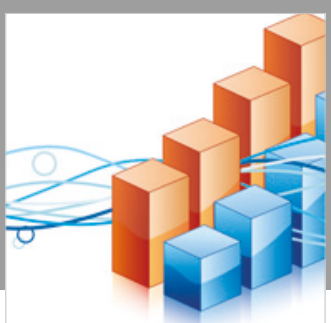

Advances in

Operations Research

\section{-n-m}
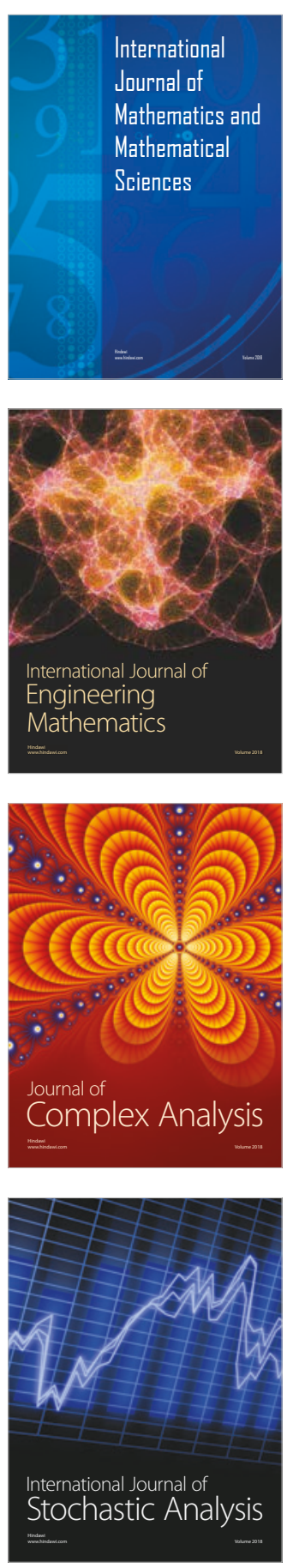
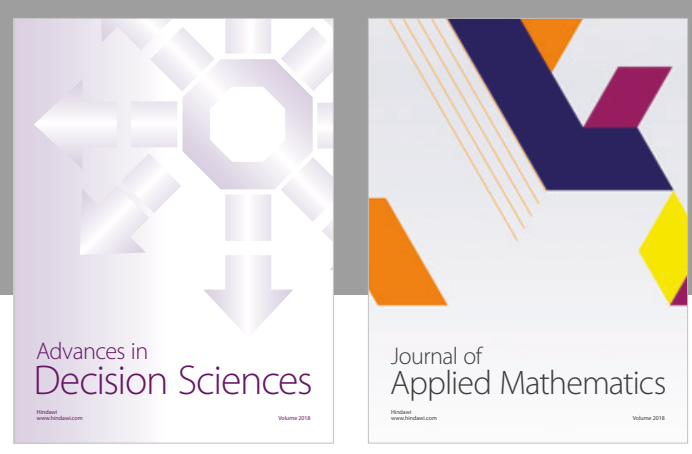

Journal of

Applied Mathematics
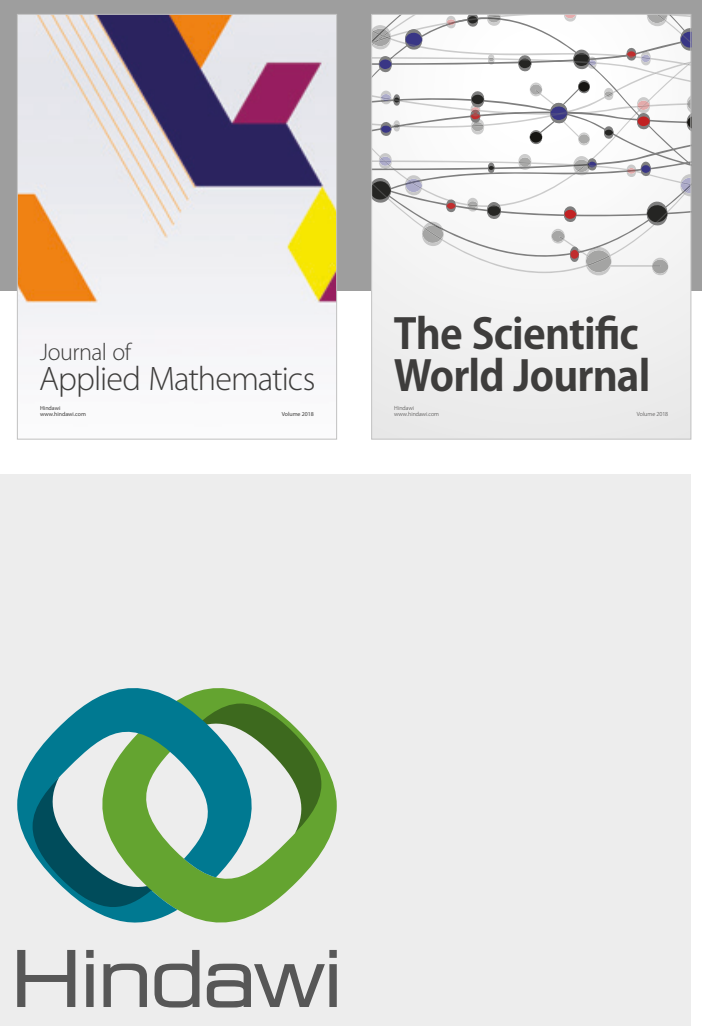

Submit your manuscripts at

www.hindawi.com

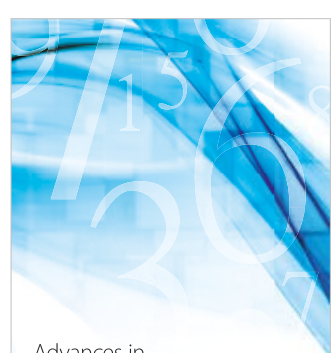

Advances in
Numerical Analysis
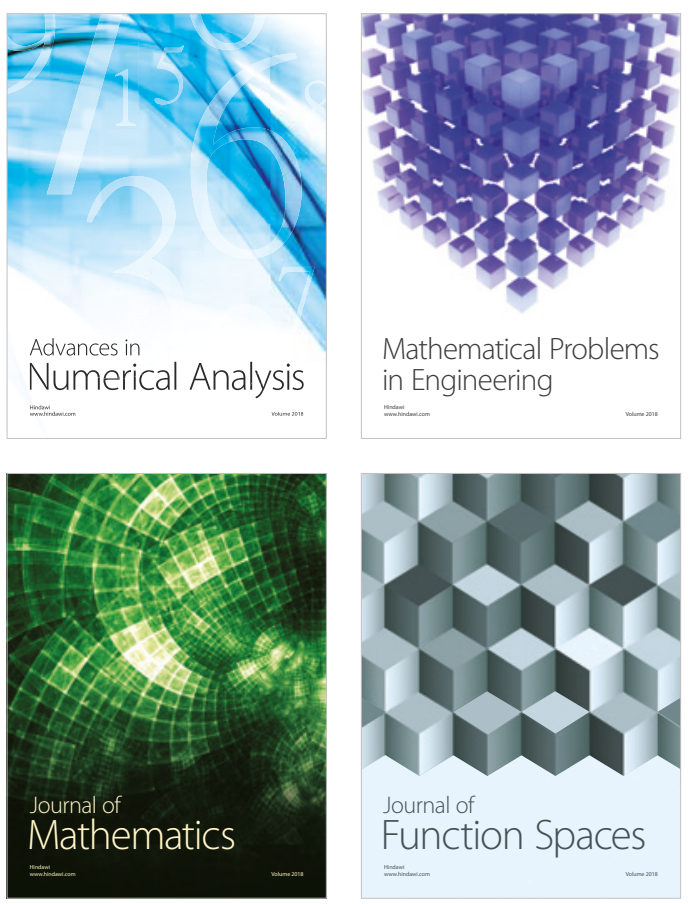

Mathematical Problems in Engineering

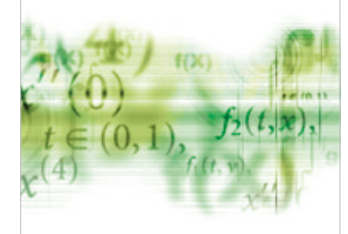

International Journal of

Differential Equations

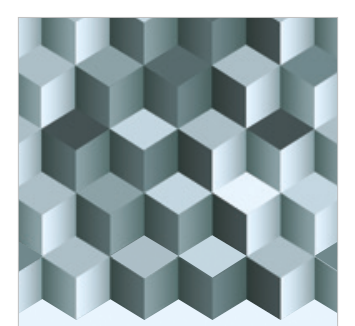

Journal of

Function Spaces

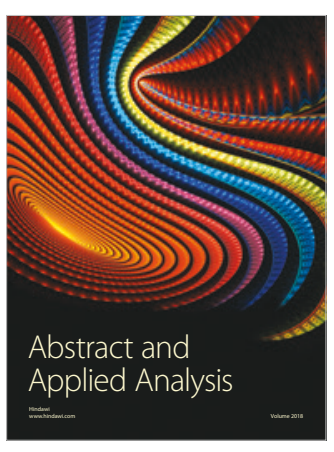

The Scientific

World Journal

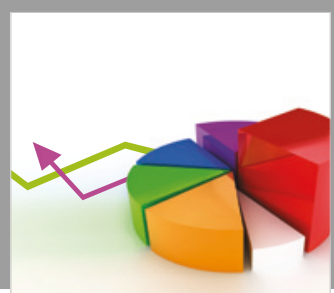

Journal of

Probability and Statistics
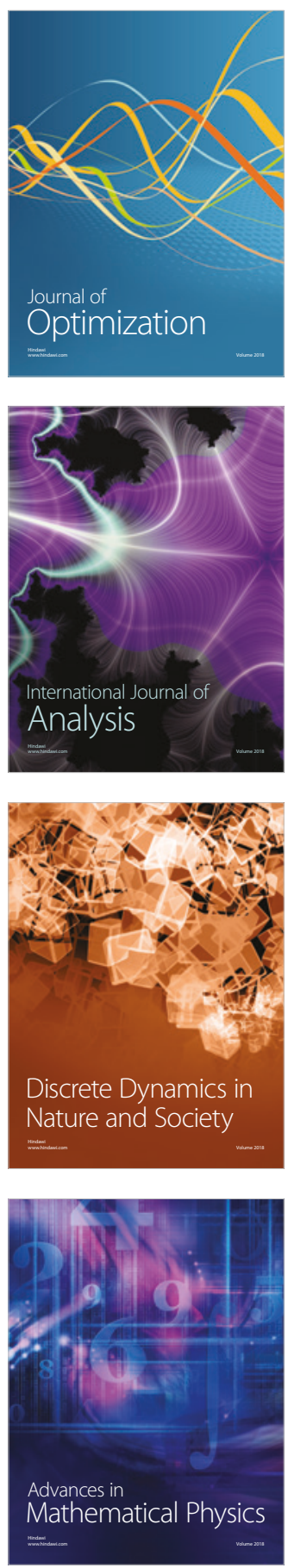